\title{
MODELING ENVIRONMENTAL IMPACTS OF PLANKTON RESERVOIRS ON CHOLERA POPULATION DYNAMICS
}

\author{
Guillaume Constantin de Magny ${ }^{1}$, Christian Paroissin ${ }^{2}$, Bernard Cazelles ${ }^{3}$, \\ Michel De Lara ${ }^{4}$, Jean-François Delmas ${ }^{5}$ and Jean-François Guégan ${ }^{6}$
}

\begin{abstract}
Cholera remains a major public health problem with significant mortality, and numerous re-emergences have been observed in the last decade in many developing countries. Previous analyses have suggested a complex process for cholera disease emergence and spread, particularly related to environmental factors associated to aquatic habitats. To disentangle the complexity of these ecological and epidemiological processes and to understand the dynamics of cholera epidemics, mathematical models are needed. Here we review the state-of-the-art of cholera models before proposing a modified model that integrates some influential environmental drivers. Particularly, as statistical analyses have revealed that chlorophyll a concentration had a significant influence over cholera epidemics our model incorporates this association, we suggest a new model where the disease starts with a bloom of phytoplankton, and then spreads in human community.
\end{abstract}

Résumé. Le choléra demeure un grave problème de santé publique avec une mortalité importante et avec de nombreux phénomènes de ré-émergences ces dix dernières années dans les pays en développement. Les analyses antérieures ont évoqué des processus complexes à l'origine de la dynamique de la maladie et plus particulièrement des relations avec les écosystèmes aquatiques et les facteurs environnementaux associés. Les modèles mathématiques sont nécessaires pour améliorer notre compréhension de la complexité de ces processus écologiques et épidémiologiques, et pour mieux appréhender la dynamique des épidémies de choléra. Ici, nous passons en revue l'état de l'art des modèles sur le choléra avant de proposer un modèle modifié intégrant des forçages environnementaux. En particulier, des analyses statistiques ayant révélé que la concentration en chlorophylle-a avait une influence significative sur lesépidémies de choléra, notre modèle intègre cette association et nous proposons un nouveau modèle dans lequel la maladie est initiée par un bloom phytoplanctonique puis se propage dans la population humaine.

\footnotetext{
1 Génétique et Évolution des Maladies Infectieuses, UMR CNRS/IRD 2724, IRD, BP 64501, 34394 Montpellier Cedex 5, France; e-mail: magny@mpl.ird.fr

2 MODAL'X, UFR SEGMI, Université Paris X Nanterre, 200 avenue de la République, 92001 Nanterre Cedex, France;

e-mail: cparoiss@u-paris10.fr

3 UMR CNRS 7625, Ecole Normale Supérieure, 46 rue d'Ulm, 75230 Paris Cedex, France;

e-mail: cazelles@biologie.ens.fr

4 ENPC-CERMICS, 6 avenue Blaise Pascal, Champs-sur-Marne, 77455 Marne-la-Vallée Cedex, France;

e-mail: delara@cermics.enpc.fr

5 ENPC-CERMICS, 6 avenue Blaise Pascal, Champs-sur-Marne, 77455 Marne-la-Vallée Cedex, France;

e-mail: delmas@cermics.enpc.fr

${ }^{6}$ Génétique et Évolution des Maladies Infectieuses, UMR CNRS/IRD 2724, IRD, BP 64501, 34394 Montpellier Cedex 5, France; e-mail: guegan@mpl.ird.fr 


\section{INTRODUCTION}

Cholera fever is an ancient disease which had disappeared from most of the developed countries in the last fifty years, but still reemerges in many parts of the world with serious epidemics most often localized in tropical areas. This highly contagious disease is due to the bacteria Vibrio cholerae after ingestion of contaminated water or seafood. $V$. cholerae is naturally present in the environment and is autochthonous in many coastal and estuarine ecosystems $[14,15,20]$. This bacteria is strongly associated with both phytoplanktonous and zooplanktonous organisms forming commensal or symbiotic relationships $[11,22,48]$.

Any changes in the density of $V$. cholerae reservoirs may imply modifications in the bacteria density in the environment [10,21]. In this context, any climatic and/or environmental changes are potentially responsible for the emergence of cholera disease in human populations [10,31,41, 46, 49].

Despite the importance of sanitary conditions and wealth in cholera epidemics, and the indisputable rise of safe structures and sewage treatment in industrialized nations, and even in some developing countries, cholera is re-emerging very recently in many tropical countries like in Senegal ${ }^{1}$. The new emergences are really questioning about the exact factors responsible of disease outbreaks in spite of better quality of life and sanitary conditions improvement in many parts of the world.

Colwell and Huq [11] were the first to propose a model for cholera transmission based on environmental parameters. Lipp et al. [30] revisited this previous model and suggested a scaling up-and-down scenario to interpret the significance of climate and the environment on $V$. cholerae population dynamics and its incidence in terms of cholera cases community (see figure 1 of [30]). The first mathematical model including a dynamics for cholera was studied by Capasso and Paveri-Fontana [5] in 1979. Since this period, few models also included environmental parameters. Recently, the ascession of the remote sensing data offers new perspectives of research on cholera models. One of these could be the elaboration of a more complex mathematical model with remote sensing data as indirect measurement of plankton reservoirs as input variables.

First, we will detail the epidemiological and environmental available data for two east coastal African countries. We then review mathematical models previously studied about cholera and environmental influences. Finally, we suggest a new model where the disease starts by a bloom of phytoplankton, and then spreads in the human populations.

\section{EPIDEMiOlogicAl AND ECOLOGICAL BACKGROUNDS}

In this section, we briefly recall the epidemiological and ecological context necessary for a better understanding of mathematical models as exposed in the present paper.

\subsection{Epidemiology}

Cholera is an acute intestinal infection caused by the bacteria $V$. cholerae O1 and O139. It has a short incubation period, from less than one day to five days, and produces an enterotoxin that causes a copious, painless, watery diarrhoea that can quickly leads to severe dehydration, and death may occur within 12 hours after the first symptoms [2] if treatment is not promptly given. Vomiting also occurs in most patients. In humans, $V$. cholerae infection results from ingestion of the bacteria, and depends on the size of pathogen inoculum. The incubation period for $V$. cholerae can range from several hours to five days, and again is dependent in part on the inoculum size [28]. In one volunteer study, five of nine healthy American prison inmates developed disease after ingestion of inocula ranging from $10^{8}$ to $10^{11} \mathrm{~V}$. cholerae serotype $\mathrm{O} 1$ organisms [6]. When stomach acidity was neutralized with sodium bicarbonate (two grams immediately prior to administration of the inoculum) attack rate of $90 \%$ was seen with an inoculum of $10^{6}[6]$. Food has a buffering capacity comparable to that seen with sodium bicarbonate. Ingestion of $10^{6}$ vibrios with food such as fish and rice resulted in the same hight attack rate as when this inoculum is administered with buffer (Levine et al. [28], cited in Kaper et al. [25]). Cholera is spread by contaminated water and food. Sudden large outbreaks are usually caused by a contaminated water

${ }^{1}$ W.H.O. website : www. who.int/csr/don/2004_11_02/en/index.html 
supply. The different pathways of disease transmission highlighted during the Latin America outbreak between 1991 and 1994 are the following [51]:

- water-borne: municipal water, surface water, putting hands in water vessel;

- food-borne: street vendor's foods, street vendor's beverages, street vendor's ices, leftover rice, fruits/vegetables;

- seafood: uncooked seafood, cooked seafood.

\subsection{Ecology of $V$. cholerae}

The main reasons in the search for external forcing, i.e. environmental and climatic drivers, responsible for more or less cholera periodic resurgences, are the marked seasonality of the disease and the often quoted simultaneous appearance of cases at different locations [17,47]. This seasonal pattern is remarkable but varies geographically in endemic area. $V$. cholerae, is a part of the normal, free living (autochthonous) bacteria flora in estuarine areas, marine and brackish waters $[13,14]$. Climatic factors such as water temperature would drive seasonality through their direct influence on the abundance and/or toxicity on $V$. cholerae in the environment [45], or alternatively, through their indirect influence on other aquatic organisms such as zooplankton, phytoplankton (marine microphytes, freshwater, green algae and blue-green algae) and macrophytes (marine and fresh water macrophytes), to which the pathogen is found to be attached [13,22-24]. For example, monsoon, floods and droughts, temperature in aquatic reservoirs or modifications of water levels, salinity and $\mathrm{pH}$ were reviewed by Pascual et al [40]. However, quantitative studies of climate influences on seasonality of the disease are few [40]. Ideally, to verify the sequence of events linking ocean parameters, e.g., plankton blooms, which are linked to cholera cases, the exploration of numerous research fields is necessary [31]. But it is both difficult, expensive and time-consuming to obtain such data [31]. Among physical factors, temperature perhaps has the most direct and significant effect on the ecology of most bacteria. Concerning the $V$. cholerae, warmer temperatures in combination with elevated $\mathrm{pH}$ and plankton blooms can influence its attachment, growth, and multiplication in the aquatic environment, particularly in association with copepods [19] (cited in [7,11,30]). Commonly, phytoplankton blooms are strongly associated with the development of zooplankton blooms [26], which both have an impact upon the $V$. cholerae life-cycle. Phytoplankton masses and movements can be monitored by Remote Sensing Imagery using chlorophyll a concentration as a proxy, and some recent researches have started to establish a model tracking the spatial and temporal development of phytoplankton blooms in relation to outbreaks of cholera $[12,31]$.

\section{REVIEW OF MATHEMATiCAL MODELS}

To our knowledge, the first mathematical model including a dynamics for cholera was studied by Capasso and Paveri-Fontana [5] in 1979. Their model had two variables (see hereafter 2.1): the mean concentration of $V$. cholerae (measured in bacteria $/ \mathrm{cm}^{3}$ ) and the number of infected people. The model was used to describe the 1973's cholera epidemic in the town of Bari (Italy).

Two decades later, Codeço [9] proposed, in 2001, an extension of Capasso's model. She included a dynamics of the susceptible population in order to study the long term dynamics of cholera (see hereafter 2.2). Thus, her model contained three variables: the number of susceptible individuals, the number of infected and the concentration of toxigenic $V$. cholerae in water (measured in cells $/ \mathrm{ml}$ ).

More recently, Pascual et al. [40] reviewed some quantitative facts about cholera and climate. In a short section, they proposed a more general model with four variables (see hereafter 2.3): the number of susceptible individuals, the number of infected, the number of fomites (or bacterial abundance) and the water volume, but the authors did not really go further with the model proposed, e.g. as doing simulations against real data cases.

We also present in the section 2.4 some other models which appear to be more or less related to our model (see the following section). 
Indeed, except for the model proposed by Capasso and Paveri-Fontana [5], all the mathematical models presented here are based on the so-called SIR model (see for instance [18,36,52]). In such model, $S$ represents the susceptible population, $I$ the infected one, and $R$ the removed one.

\subsection{Capasso's model}

Capasso and Paveri-Fontana [5] proposed the first model of cholera epidemics involving a dynamics for bacteria population. The application of their model was a cholera epidemic in Bari (Italy) in 1973. This model is reduced to a system of two differential equations

$$
\left\{\begin{array}{l}
\frac{d x_{1}}{d t}=-a_{11} x_{1}+a_{12} x_{2} \\
\frac{d x_{2}}{d t}=g\left(x_{1}\right)-a_{22} x_{2}
\end{array}\right.
$$

where $x_{1}$ is the mean concentration of $V$. cholerae in the sea water surrounding the city of Bari, and $x_{2}$ is the mean number of infective people in the community. The function $g$ has to satisfy some assumptions about its regularity. First, they considered a general form for $g$, and then they studied the case of a continuous piecewise-linear form for $g$.

\subsection{Codeço's model}

Codeço [9] proposed a model with a constant human population size, $H$, described by the following system of differential equations

with

$$
\left\{\begin{aligned}
\frac{d S}{d t} & =n(H-S)-a \lambda(B) S \\
\frac{d I}{d t} & =a \lambda(B) S-r I \\
\frac{d B}{d t} & =B\left(n_{b}-m_{b}\right)+e I
\end{aligned}\right.
$$

$$
\lambda(B)=\frac{B}{K+B}
$$

The term $\lambda(B)$ can be interpreted as the rate or the probability for a susceptible to be infected by contaminated water. This probability is an increasing function of the concentration of toxigenic $V$. cholerae. Codeço chose a logistic form for the probability such that $\lambda(B)=0.5$ if $B=K$. In fact, $K$ is related to the inoculum size, which is the total number of bacteria necessary to cause the disease, i.e. $10^{6}$ to $10^{8}$ for $\mathrm{V}$. cholerae.

Table 1 gives the list of variables and parameters used in Codeço's model.

Codeço considered three hypothetical human communities, corresponding to three different sets of values for the parameter's values (see Table 2). The initial values remained fixed: $S(0)=H, I(0) \geq 0$ and $B(0)=0$. Figures 1 are redrawn from the article by Codeço.

- Community 1 (cholera-free): in this case, the equilibrium quantities are $S^{*}=H, I^{*}=0$ and $B^{*}=0$.

- Community 2 (epidemic): with the parameters values in Table 2 and $I(0)=1$, we get the trajectories as given by Codeço. Figure $1 \mathrm{~A}$, gives the short-term evolution of the four variables of the model. This figure is a little misleading since one can imagine that the number of susceptibles is stationary. Indeed the number of susceptibles reaches its initial value $H(=10,000$ ind.) as the time goes to infinity.

- Community 3 (endemic): with the parameters values of Table 2 and $I(0)=1$, we get the following behaviors figures (Figure 1, B) for the evolution of the variables $S, I$ and $B$ on the long-term evolution. The number of susceptibles oscillates around a value $S_{C}=\frac{r K\left(m_{b}-n_{b}\right)}{a e}$. 
TABLE 1. Codeço's model with the list of variables and parameters used in the model.

\begin{tabular}{cl}
\hline \hline Symbol & Description \\
\hline \hline Variables & \\
\hline$S$ & number of susceptible individuals (ind.) \\
$I$ & number of infected individuals (ind.) \\
$B$ & concentration of toxigenic $V$. cholerae in water (cells $/ \mathrm{ml})$ \\
\hline Parameters & \\
\hline$H$ & total human population (ind.) \\
$a$ & human birth and death rates $\left(\right.$ day $\left.^{-1}\right)$ \\
$K$ & rate of exposure to contaminated water $\left(\right.$ day $\left.^{-1}\right)$ \\
$r$ & concentration of $V$. cholerae in water that yields $50 \%$ chance of catching cholera $($ cells $/ \mathrm{ml})$ \\
$n_{b}-m_{b}$ & difference between the growth and loss rates of Vibrio cholerae \\
& in the aquatic environment $\left(\right.$ day $\left.^{-1}\right)$ \\
$e$ & contribution of each infected people to the population of $V$. cholerae in the aquatic \\
& environment (cells $/$ ml day $^{-1}$ person $\left.^{-1}\right)$ \\
\hline
\end{tabular}

TABLE 2. Codeço's model - list of parameters for three distinct hypothetical communities.

\begin{tabular}{cccc}
\hline \hline Parameters & Community 1 & Community 2 & Community 3 \\
\hline \hline Expected cholera dynamics & cholera-free & epidemic & endemic \\
\hline$H$ & 10,000 ind. & 10,000 ind. & 10,000 ind. \\
$n$ & 0.0001 & 0.0001 & 0.001 \\
$a$ & 0.5 & 1 & $1 \%$ \\
$K$ & $10^{6}$ cells $/ \mathrm{ml}$ & $10^{6}$ cells $/ \mathrm{ml}$ & $10^{6}$ cells $/ \mathrm{ml}$ \\
$r$ & 0.2 & 0.2 & 0.2 \\
$n_{b}-m_{b}$ & -0.33 & -0.33 & -0.33 \\
$e$ & 10 cells $/ \mathrm{ml}$ & 10 cells $/ \mathrm{ml}$ & 10 cells $/ \mathrm{ml}$ \\
\hline
\end{tabular}

(A)
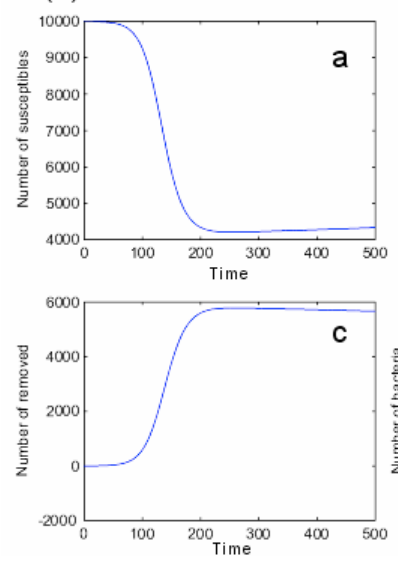
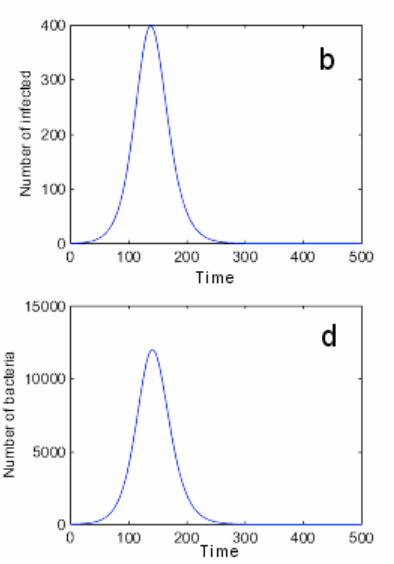

(B)
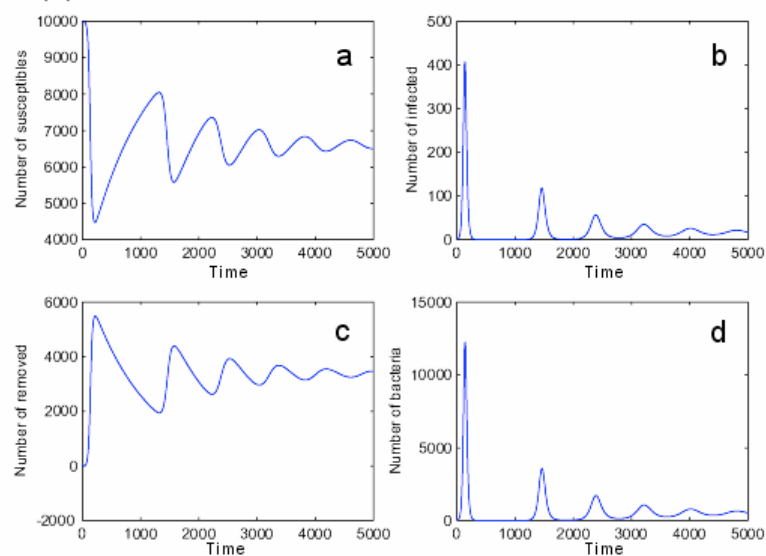

Figure 1. Codeço's model - time evolution in (A) epidemic situation, and (B) endemic situation of the four variables, (a) Susceptibles, (b) Infected, (c) Removed, (d) Concentration in bacteria within the aquatic environment. 
Codeço [9] concluded that "in the limit, [...] endemism in sanitized communities requires a permanent reservoir while endemism in poor communities requires just transient reservoirs (and a sufficiently high turnover of susceptible)". This result suggests that cholera endemism in the US Golf Coast, for example, may be due to a permanent reservoir of $V$. cholerae. During the last two decades, evidence has been accumulated from Australia and the United States, showing that both these countries might have environmental reservoirs for toxigenic $V$. cholerae $\mathrm{O} 1$ [3]. In some African regions where poor conditions occur, a situation of endemism can be maintained even in the absence of an environmental reservoir [33,53]. This conclusion - as well as the fact that the Codeço's model does not take into account the possibility that the infected people contaminate the healthy people directly - will lead us to propose, in the present work, a new model based on Codeço's model. Our model integrates the possibility for infected people to supply the susceptible compartment with toxic $V$. cholerae bacteria.

\subsection{Pascual et al. model}

Pascual et al. [40] in section 5 of their paper deal with mathematical models. After reviewing very briefly the mathematical models previously studied, Pascual and collaborators suggested a new model but without any further explanations on it (either theoretically or based on simulations). Pascual's tentative model is described by the following set of differential equations:

$$
\left\{\begin{aligned}
\frac{d S}{d t} & =(b-d)(H-S-I)+\rho I-\beta \frac{S F}{k W+F} \\
\frac{d I}{d t} & =\beta \frac{S F}{k W+F}-(d+\rho+\alpha) I \\
\frac{d F}{d t} & =(r-\mu) F+\lambda I \\
\frac{d W}{d t} & =p+s-D W
\end{aligned}\right.
$$

Table 3 gives the list of variables and parameters used in Pascual et al. model. Notice that they envisaged that some parameters ( $p$ and $s$ ) could vary in time (on an annual cycle).

\subsection{Other models}

Notice that there exists some other published mathematical models of cholera epidemics, but without any consideration on the existence of an ecological component in the bacteria life-cycle. However some of them are here interesting to mention. In particular, Pourabbas et al. [43] studied a model with seasonal fluctuations and temporary immunity, and interestingly they fitted observed data for three distinct countries (El Salvador, Nicaragua and Somalia) during the course of an epidemic from 1993 to 1994 to their model predictions. Note that the period is not exactly the same for the three countries. They concluded that the estimate of number of infected $\mathrm{I}(\mathrm{t})$ is expected to be reasonably accurate if this quantity has slow temporal variations. If high-frequency components are present in the time behaviour of I, they cannot be recovered by the described procedure.

\section{A mathematical MOdel With TEMPorary imMUnity INCLUDING ENVIRONMENTAL IMPACT}

In this section, we propose a new mathematical model partly inspired by two papers mentioned previously (Codeço [9] and Pascual et al. [40]) which consider an ecological, environmental component to V. cholerae life-cycle. 
TABLE 3. Pascual's model with the list of variables and parameters used in the model.

\begin{tabular}{cl}
\hline \hline Symbol & Description \\
\hline \hline Variables & \\
\hline$S$ & number of susceptible individuals \\
$I$ & number of infected individuals \\
$F$ & number of fomites (or bacterial abundance) \\
$W$ & water volume \\
\hline Parameters & \\
\hline$H$ & total human population (not specified in the paper) \\
$b$ & host per capita birth rate \\
$d$ & host per capita death rate \\
$\beta$ & infection rate at which fomites cause infection in susceptible hosts \\
$\rho$ & recovery rate of infected individuals \\
$k$ & scaling constant that modifies water volume to determine number of fomites \\
$\alpha$ & required to induce infection in a susceptible \\
$r$ & increased mortality rate of infected hosts \\
$\mu$ & reproductive rate of free-living fomites (may be a function of temperature) \\
$\lambda$ & death rate of free-living infective stages \\
$p$ & rate at which infected produce infective stages \\
$s$ & precipitation rate (may vary on an annual cycle) \\
$D$ & river flow rate (may vary on an annual cycle) \\
& drainage rate of water downstream from site of infection per volume of water \\
\hline
\end{tabular}

\subsection{Description of observed data}

For a large number of African coastal countries, we dispose of epidemiological and ecological data: number of cholera cases and concentration of chlorophyll a (measured in $\mathrm{mg} / \mathrm{m}^{3}$ ) in marine coastal environments. Here we only consider two countries: Mozambique and Somalia. Figure 2 illustrates the number of cholera cases and the chlorophyll a concentration, for these two African countries.

\subsubsection{Cholera cases}

The total number of cholera cases comes from the Weekly Epidemiological Record published by the World Health Organization (W.H.O.), which are available at the WHO website ${ }^{2}$. Figure 3 shows an extract of one Weekly Epidemiological Record (76th year, number 41, 12 October 2001). Generally, each country gives to the W.H.O. headquarters a notification of the number of cases and deaths for a certain period, and this period may differ in time and by country.

For each of the two East African countries, we recorded in a database the number of cholera for each month between January 1975 and December 2002. Since the periods of notification are not identical for a given time series, we transformed the data by a linear interpolation to get monthly data. For instance, from the extract of the Weekly epidemiological record illustrated on figure 3, we consider that in Mozambique there was 112.36 cases in August 2001 and 505.63 cases in September 2001 (provided that no other notifications were given between August and September 2001, for the Mozambique). This data transformation was done for the sake of simplicity; it should certainly be revised in future works.

\footnotetext{
${ }^{2}$ W.H.O. website : www. who.int/wer/en
} 

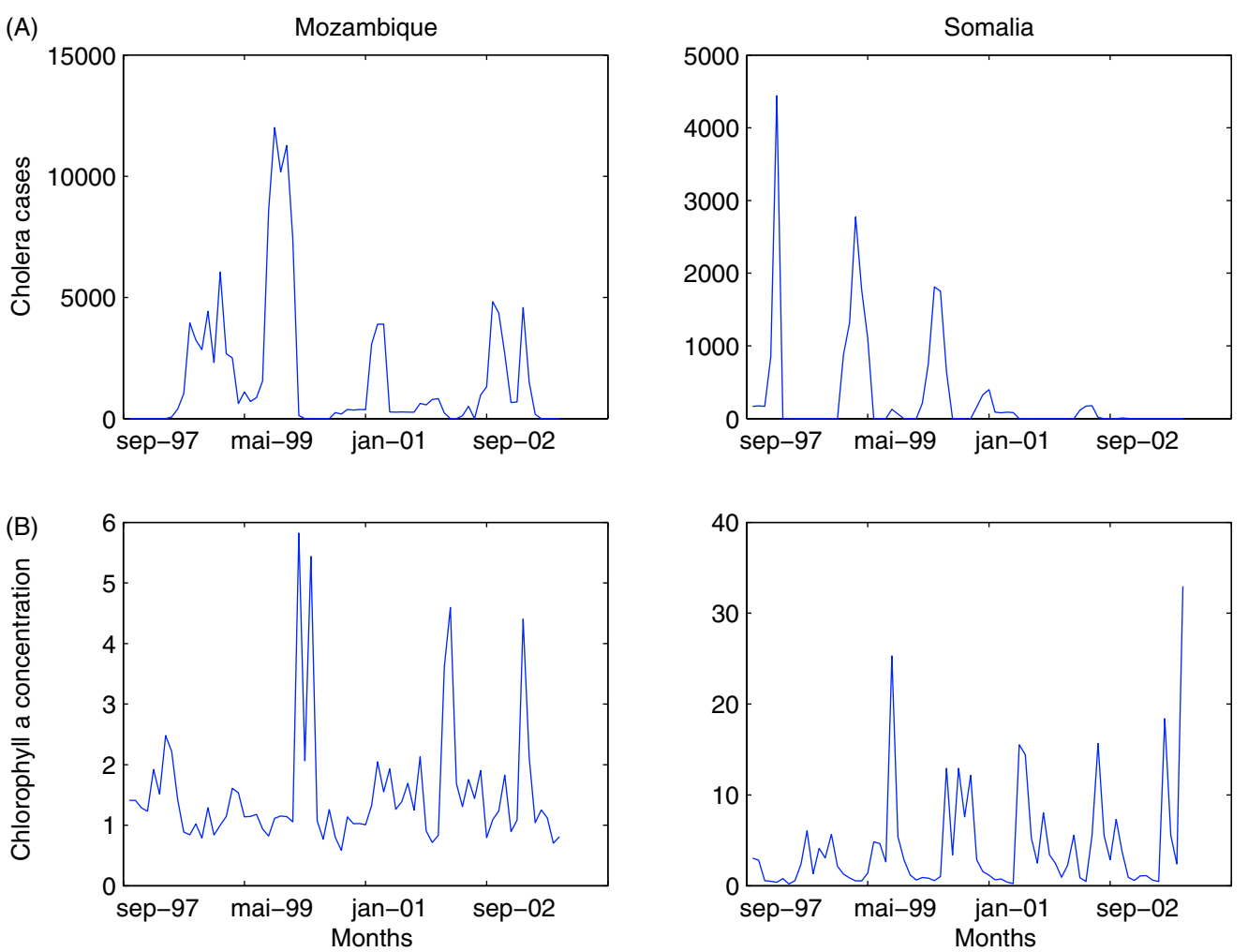

Figure 2. (A) Number of cholera cases for Mozambique and Somalia based on corrected monthly data (source: W.H.O. reports), and (B) maximum concentration of chlorophyll a at $50 \mathrm{~km}$ off the coast (source: N.A.S.A.).

\section{INTERNATIONALHEALTH REGULATIONS / RĖGLEMENT SANITAIRE INTERNATIONAL}

Notifications of diseases received from 5 to 11 October 2001 / Notifications de maladies reçues du 5 au 11 octobre 2001 Cholera / Choléra

\begin{tabular}{|c|c|}
\hline Africa / Afrique & $\begin{array}{l}\text { Cases / Deaths } \\
\text { Cas / Décès }\end{array}$ \\
\hline Guinea/ Guinée & $\begin{array}{l}\text { 6.VIII-23.JX } \\
155\end{array}$ \\
\hline Mozambique & 28.VIII-18.IX \\
\hline & 618 \\
\hline Togo & 17.VII-30.IX \\
\hline
\end{tabular}

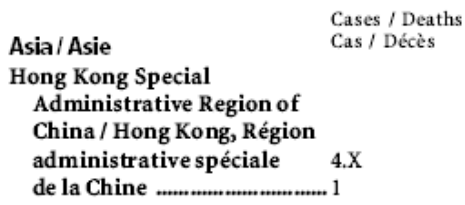

FiguRE 3. Extract from one Weekly Epidemiological Record (76th year, n41, 12 October 2001) 


\subsubsection{Chlorophyll a concentration}

The weekly data for the oceanic concentration of phytoplankton was estimated by SeaWiFS derived chlorophyll a concentration (measured in $\mathrm{mg} / \mathrm{m}^{3}$ ) data from September 1997 to August 2002 (see the Distributed Active Archive Center ${ }^{3}$; see also [39]). Image data were downloaded from the NASA web site. The figure 4 is an example of such an image.

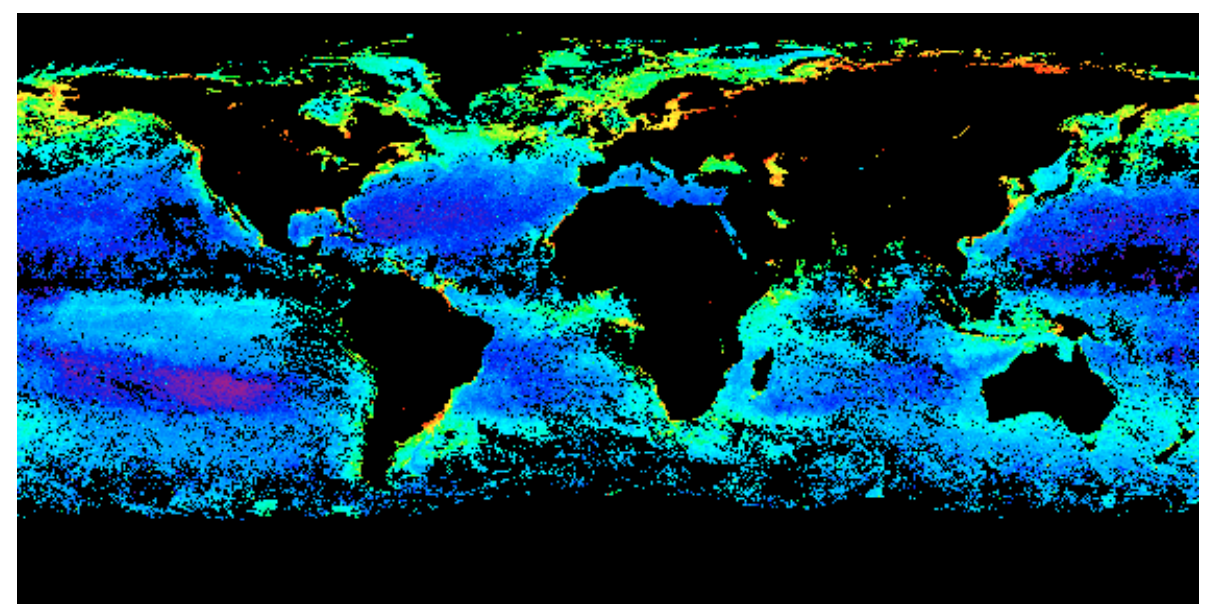

FiguRE 4. SeaWiFS-derived chlorophyll concentration for August $21^{\text {th }} 2002$ to August $28^{\text {th }} 2002$.

Then, images were imported into Seas-View, an image processing software (geographic information system) developed by Martin Desruisseaux (IRD) within the framework of OpenSource project SEAGIS ${ }^{4}$. At each unit of time (weekly data), the chlorophyll a value of pixels in the images were extracted from respectively 25 and 20 points located at $50 \mathrm{~km}$ off the coast of Mozambique and Somalia respectively, each being distant of $100 \mathrm{~km}$ from the other. Then, we retained the maximum value of the chlorophyll a concentration at these points. We considered that the maximum of chlorophyll a concentration could be responsible of the beginning of epidemic.

\subsection{A continuous time model}

As previous reviewed models, our mathematical model will also be based upon a classical SIRS modelling (see for instance $[18,36,52]$ ), and it will integrate the first two assumptions detailed in the following subsection.

\subsubsection{Assumptions}

- Growth of the human population: in order to consider long time series, we assume that the population is increasing with time. Since the infective period is rather short (see later for a discussion about this duration), only susceptible and recovered individuals will have offspring. We will also assume that recovered individuals may transmit their immunity to their offspring.

- Temporary immunity: in contrast with previously studied mathematical models (see the previous section on Codeço's model [9] and Pascual et al. model [40]), we here consider a class for the recovered individuals which may develop an immunity against cholera. The strongest evidence for the existence of infection-derived immunity to $V$. cholerae comes from volunteer studies conducted at the University of Maryland. These studies show that volunteers experimentally infected with virulent $V$. cholerae are solidly protected against illness upon subsequent re-infection with the bacteria [6, 29]. Protection

\footnotetext{
${ }^{3}$ DAAC-NASA website : http://daac.gsfc.nasa.gov
}

$4_{\text {http: //seagis. sourceforge.net }}$ 
against disease conferred by an initial infection with a classical strain lasts for at least 3 years, the longest interval tested within the same biotype [27]. Epidemiological studies in Bangladesh also support the idea that substantial protective immunity is generated by infection with $V$. cholerae. Recently, Clemens et al. [8] also found evidence of infection-derived immunity. They noticed striking differences between biotypes of Vibrio: an initial infection with classical strain of $V$. cholerae was associated with complete protection, while initial infections with the specific El Tor strains were associated with insignificant protection. The best correlation with protection is a serum vibriocidal antibody response. This assay measures the killing of $V$. cholerae cells in the presence of immune sera and complement. Studies in Bangladesh have shown that the prevalence and geometric mean titer of vibriocidal antibody increases with age and that, for every twofold increase in geometric mean vibriocidal titer, the incidence of cholera falls by approximately one-half $[34,35]$.

This leads us to distinguish between dead individuals $(D)$ and recovered individuals $(R)$, in contrast with the previous mathematical models by Pascual et al. where they are considered as belonging to the same group of removed individuals (as it is done in the basic version of the SIR model).

- Concentration of chlorophyll a: we retain the maximum value of the chlorophyll a concentration along the coast because we consider that it could be responsible of the beginning of epidemic.

The ecological component of the model is derived from Codeço's model [9]. We finally obtain the following equations:

$$
\left\{\begin{aligned}
\frac{d S_{t}}{d t} & =(b-d) S_{t}-\beta S_{t} I_{t}-\frac{\gamma S_{t} C_{t-\delta}}{k+C_{t-\delta}}+\rho^{\prime} R_{t} \\
\frac{d I_{t}}{d t} & =\beta S_{t} I_{t}+\frac{\gamma S_{t} C_{t-\delta}}{k+C_{t-\delta}}-\tau I_{t} \\
\frac{d D_{t}}{d t} & =\lambda \tau I_{t}+d\left(S_{t}+R_{t}\right) \\
\frac{d R_{t}}{d t} & =(1-\lambda) \tau I_{t}+(b-d) R_{t}-\rho^{\prime} R_{t}
\end{aligned}\right.
$$

Time is measured in months. This choice is natural since the epidemiological data are recorded more or less monthly.

The human population size is denoted by $H$. Since a recovered individual looses his immunity after a while, we have to distinguish dead individuals from recovered individuals as previously said. Hence the human population is divided into four classes: susceptible individuals $(S)$, infected individuals $(I)$, recovered individuals $(R)$ and dead individuals $(D)$ : thus $H=S+I+R$. We will not assume that the population size is constant in order to be able to consider, if needed, long time series data for disease. Figure 5 summarizes the possible transitions between the different variables.

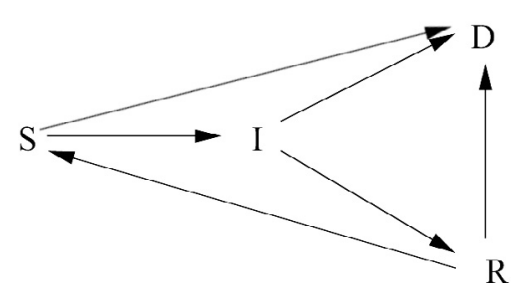

FIGURE 5. SIDR model as used in this work with transition between the different possible states.

Table 4 gives the list of variables and parameters used in our present model. 
TABLE 4. SIDR model - list of variables and parameters

\begin{tabular}{cl}
\hline \hline Symbol & Description \\
\hline \hline Variables & \\
\hline$S$ & number of susceptible individuals \\
$I$ & number of infected individuals \\
$D$ & number of dead individuals (not only due to cholera) \\
$R$ & number of recovered individuals \\
$C$ & concentration of chlorophyll a $\left(\mathrm{mg} / \mathrm{m}^{3}\right)$ \\
\hline Parameters & \\
\hline$H$ & initial total population \\
$b$ & human birth rate in $\%$ (only for susceptible and recovered individuals) \\
$d$ & human death rate in \% (only for susceptible and recovered individuals) \\
$\delta$ & delay parameter (month $\left.{ }^{-1}\right)$ \\
$\beta$ & contact infection rate from infected individuals to susceptible individuals $\left(\mathrm{month}^{-1}\right)$ \\
$k$ & quantity of phytoplankton yields $50 \%$ chance of catching cholera $\left(\mathrm{mg} / \mathrm{m}^{3}\right)$ \\
$\tau$ & removed rate (month $\left.{ }^{-1}\right)$ \\
$\lambda$ & case-fatality rate $(\%)$ \\
$\rho^{\prime}$ & loss of immunity rate (month $\left.{ }^{-1}\right)$ \\
$\gamma$ & contact infection rate from contaminated water to susceptible individuals $\left(\mathrm{month}^{-1}\right)$ \\
\hline
\end{tabular}

Our present model also contains one environmental variable : $C$ is the maximum chlorophyll a concentration in the sea surface. This variable has its own dynamics which is really independent of the epidemiological variables. However, this variable plays a crucial role in the emergence of a cholera epidemic. The term involving $C$ in the model is similar to the one used in Codeo's model (i.e. a saturation dose response), except that we here introduced a time delay parameter $\delta$. In this model, we introduced a delay parameter for the concentration of chlorophyll a, since this quantity is measured in the sea at 50 kilometers of the coast line. Auto- and crosscorrelations were computed between two time series (cholera cases and chlorophyll a concentration). The results, not presented in this document, show a 14 weeks delay between the two series with chlorophyll a in being in advance on the cholera ( $\mathrm{G}$. Constantin de Magny, thesis in preparation).

The newly introduced parameters are the following: $b$ and $d$ are the human birth rates (only for susceptible individuals) and death rates, respectively. These parameters could depend on time (especially if we consider long time series). Notice that, in order to have a constant human population size, one has $b=d$. For a review about models with exponentially changing size and other models, see the section 3 of [18].

The parameter $\beta$ is the contact infection rate (from infected individuals to susceptible individuals). Indeed, it is not a direct contact infection as in classical SIR model, but rather the main way of transmission of the disease (essentially food-borne). The parameter $\gamma$ corresponds to the contamination of susceptible individuals by direct contact with contaminated sea water: $\gamma$ is the rate of exposure to contaminated water. The parameter $k$ is related to the size of inoculum as detailed in paragraph 1.1, which also appears in Codeo's model [9].

The first transmission term (the one involving the variables $S$ and $I$ ) corresponds to the vision of 'contagionists' and the second transmission term (the one involving the variables $S$ and $C$ ) corresponds to the vision of 'localists'.

Individuals stay infected during $1 / \tau$ units of time, in average. Either an infected individual dies or becomes immune. The proportion of dead individuals because of cholera is the case-fatality rate (CFR) and equal to $\lambda$. A recovered individual becomes again susceptible after a mean duration of $1 / \rho^{\prime}$ units of time. 


\subsection{Parameters estimation}

Model (4) depends on four initial conditions and nine parameters, among which some are known for geographical or biological reasons. The remaining initial conditions and parameters $-I_{0}, R_{0}, \beta, \gamma$ and $k-$ will be estimated by least-square minimization between observations and computed ouputs.

For the initial condition of the differential system (4), we choose $S_{0}=H-I_{0}-R_{0}$ and $D_{0}=0$. The other parameters are fixed as follows: the demographic parameters depend on the country considered, and the other ones have the same values for all countries according to biological reasons (see Table 5).

TABLE 5. SIDR model - value for fixed parameters

\begin{tabular}{ccc}
\hline \hline Parameters & Mozambique & Somalia \\
\hline \hline$b$ & 0.0033 month $^{-1}$ & 0.0038 month $^{-1}$ \\
$d$ & 0.0013 month $^{-1}$ & 0.0015 month $^{-1}$ \\
$H$ & $3,960,000$ ind. & $1,980,000$ ind. $^{-1}$ \\
$\tau$ & 15.25 month $^{-1}$ & 15.25 month $^{-1}$ \\
$\lambda$ & $8 \%$ & $8 \%$ \\
$\rho^{\prime}$ & 0.167 month $^{-1}$ & 0.167 month $^{-1}$ \\
$\delta$ & 3.5 month $^{2}$ & 3.5 month \\
\hline
\end{tabular}

The demographic parameters $b, d$ and $H$ were found on the website www . populationdata.net ${ }^{5}$, and converted into monthly rates for $b$ and $d$. For population size, we considered only the population living on the coast, and we chose $H$ equal to $33 \%$ of this number, since only a minority of individuals infected with the classical biotype of Cholera Toxin [CT]-producing $V$. cholerae may develop the most severe manifestations of the disease [16]. It was estimated that, for patients infected with the classical biotype, only $41 \%$ of people developed symptoms compared with $25 \%$ infected with the El Tor biotype.

The removed rate $\tau$ is fixed to 15.25 months $^{-1}$, which corresponds to a mean infection period of 2 days. Notice that it was fixed at 5 days in Bradley et al. [4] and Codeo [9].

The case-fatality rate (CFR) denoted by $\lambda$ is fixed to $8 \%$. However this rate may probably not be constant during a whole epidemic (this rate decreases in time from the beginning of the epidemic) and may differ across regions. On the $\mathrm{PAHO} / \mathrm{WHO}$ website, we obtained data about a cholera epidemic in Peru in 1991, and the CFR ranges between $0.25 \%$ and $17.5 \%$.

As shown by Levine et al. [27], the longest interval tested within the same biotype was three years for immunity protection. Kaper et al. [25] noticed contrasted results about protective immunity generated by infection with $V$. cholerae, and only few data are really available on this parameter. However Kaper et al. concluded on the existence of a strong protective immunity conferred by an infection. In this context, we decided to put the mean duration of loss-immunity lower than three years and fixed it at six months. This is why we have $\rho^{\prime}=0.167$ months ${ }^{-1}$. We are totally conscious that this choice may appear arbitrary.

Available epidemiological data are the number of hospitalized individuals (who will then be immune) and the number of dead individuals (due to cholera). So, the observed number of hospitalization and death $\Delta Y_{k}$ in the time interval $[(k-1) \Delta t, k \Delta t]$ is

$$
\Delta Y_{k}=\int_{(k-1) \Delta t}^{k \Delta t} \tau I_{s} d s .
$$

Hence we will be able to compare the output of our model to the data given by the World Health Organization.

\footnotetext{
${ }^{5}$ Data for Somalia: http://www.populationdata.net/somalie.html

Data for Mozambique: http://www.populationdata.net/mozambique.html
} 
For a discussion about observed data in a SIR model, see Murray [36] (p. 324), Pourrabas et al. [43] and Ng et al. [37].

The values of the other initial conditions parameters will be estimated by minimizing the sum of least-square errors between observed data and model output as follows,

$$
\inf _{I_{0}, R_{0}, \beta, \gamma, k} J\left(I_{0}, R_{0}, \beta, \gamma, k\right)=\inf _{I_{0}, R_{0}, \beta, \gamma, k} \sum_{k=0}^{N}\left|\Delta Y_{k}-\int_{(k-1) \Delta t}^{k \Delta t} \tau I_{s} d s\right|^{2},
$$

where the evolution of $I_{t}$ is described by the differential system (4). The value of horizon $N$ depends on the value of $\delta$. Indeed $N$ will be at most equal to 59 months since chlorophyll a concentration data are available from September 1997 to August 2002.

Notice that the goal function $J$ does not depend upon $\tau$ since we assume that its value is known. This differs from the classical situation when dealing with estimation in a classical SIR model (see for instance $\mathrm{Ng}$ et al. [37]).

For each model and for each country, some initial condition values and some parameters are estimated. We used the softwares Scilab ${ }^{6}$ and Matlab ${ }^{7}$. To solve (6), we tried two algorithms: the Levenberg-Marquardt algorithm which is used in the function lsqrsolve() of Scilab and the downhill simplex method (Nelder-Mead algorithm) which is used in the function fminsearch() of Matlab (for some details about these algorithms, see respectively the section 10.4 and 15.5 of $[44]^{8}$ ). Before fitting the model to the observed data, we tested these two algorithms as follows: we computed the numerical solution of the differential system with known parameters, we perturbed it by a random noise and, we estimated the parameters (starting with initial values of the parameters different from the true value of them). For this kind of problem, the downhill simplex method seems to be more efficient than the Levenberg-Marquardt algorithm (which gives a solution too far away from the true values of the parameter). Hence, we chose to fit the model to the data with the function fminsearch() of Matlab. We applied a multi-start strategy with random initial values for the unknown parameters. The result we got was not satisfying since sometimes we obtained a too large value for $k$. Thus we used the function fmincon() of Matlab which is an optimization function with constraints (this function is also based on the Nelder-Mead algorithm). We just used this function to specify an upper bound (and sometimes a lower bound) for each parameter. To end up, notice that we did not fit the data for the whole time range (since January 1998 to at most December 2002 - depending on the quality of the data).

\subsection{Numerical Results}

\subsubsection{Estimated parameters}

Model (4) depends on four initial conditions and nine parameters. The values of fixed initial conditions and parameters are summarized in Table 5 . The five values for the remaining estimated parameters are presented in Table 6, together with the lower and upper bound fed into the function fmincon() for the minimization procedure.

\subsubsection{Numerical results}

The numerical computations results were presented on Figures 6 and 7 for Mozambique and Somalia respectively.

\footnotetext{
${ }^{6}$ Downloadable at www.scilab.org

7 www.mathworks. com

${ }^{8}$ Also available on the web at www.library. cornell.edu/nr/bookcpdf.html
} 
TABLE 6. Optimal value of the parameters for the SIDR model.

\begin{tabular}{ccccccc}
\hline \hline Parameters & Mozambique & Lower bound & Upper bound & Somalia & Lower bound & Upper bound \\
\hline \hline$I_{0}$ & 37,438 & 0 & $1,188,000$ & 4,144 & 0 & 594,000 \\
$R_{0}$ & 8,920 & 0 & $1,188,000$ & 8,377 & 0 & 594,000 \\
$\beta$ & $1.76 \times 10^{-10}$ & $1.76 \times 10^{-10}$ & $1.76 \times 10^{-08}$ & $7.22 \times 10^{-08}$ & $1.76 \times 10^{-09}$ & $1.76 \times 10^{-07}$ \\
$\gamma$ & $2.18 \times 10^{-03}$ & $3.80 \times 10^{-04}$ & $3.80 \times 10^{-02}$ & $2.20 \times 10^{-04}$ & $5.05 \times 10^{-05}$ & $5.05 \times 10^{-03}$ \\
$k$ & 0.79 & $1 \times 10^{-03}$ & 10 & 0.26 & $1 \times 10^{-03}$ & 10 \\
\hline
\end{tabular}
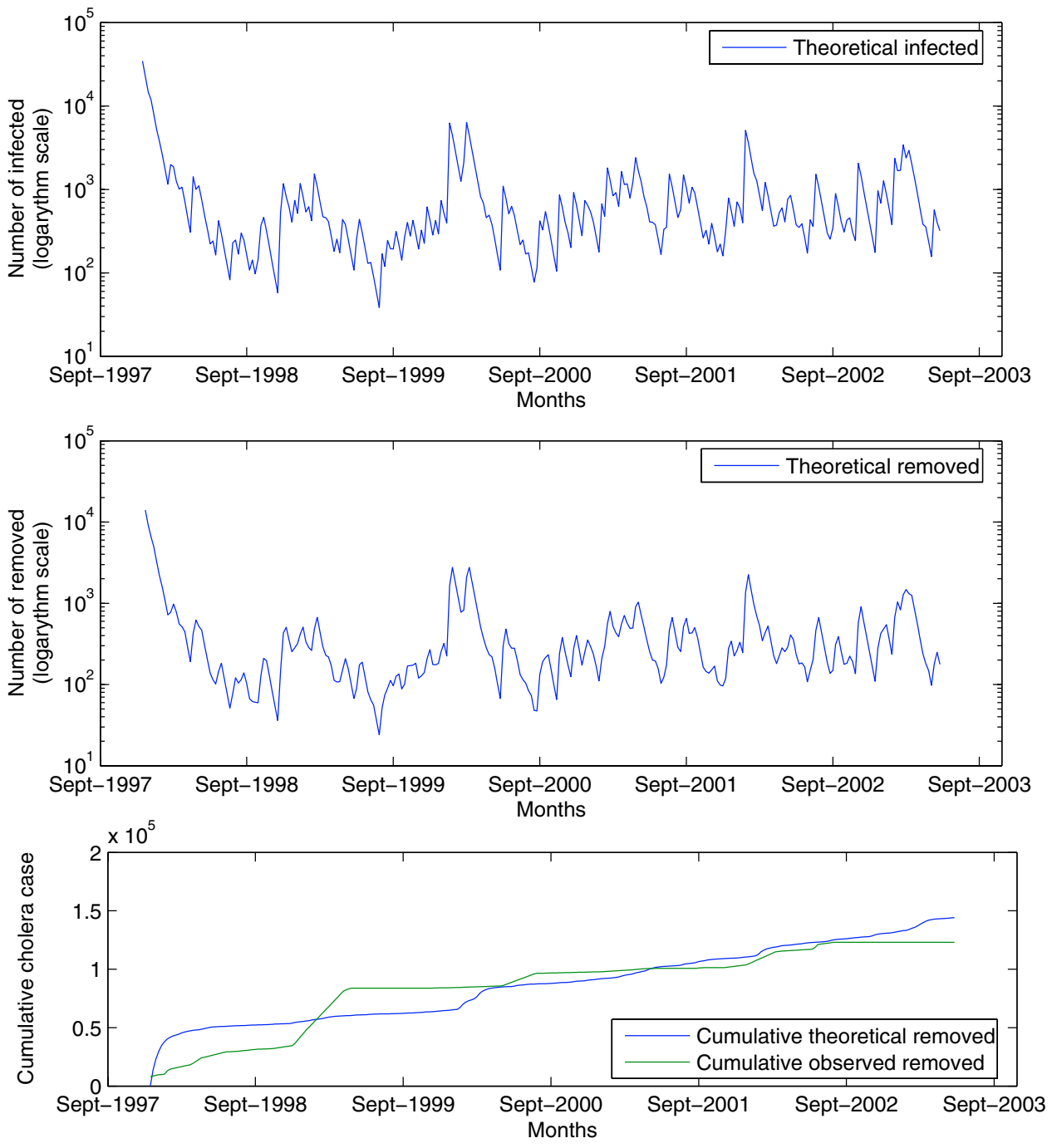

FIguRE 6. Time evolution of three variables of the SIDR model for Mozambique, Theoretical Removed, Theoretical Infected, and both Cumulative Theoretical and Observed Removed. 

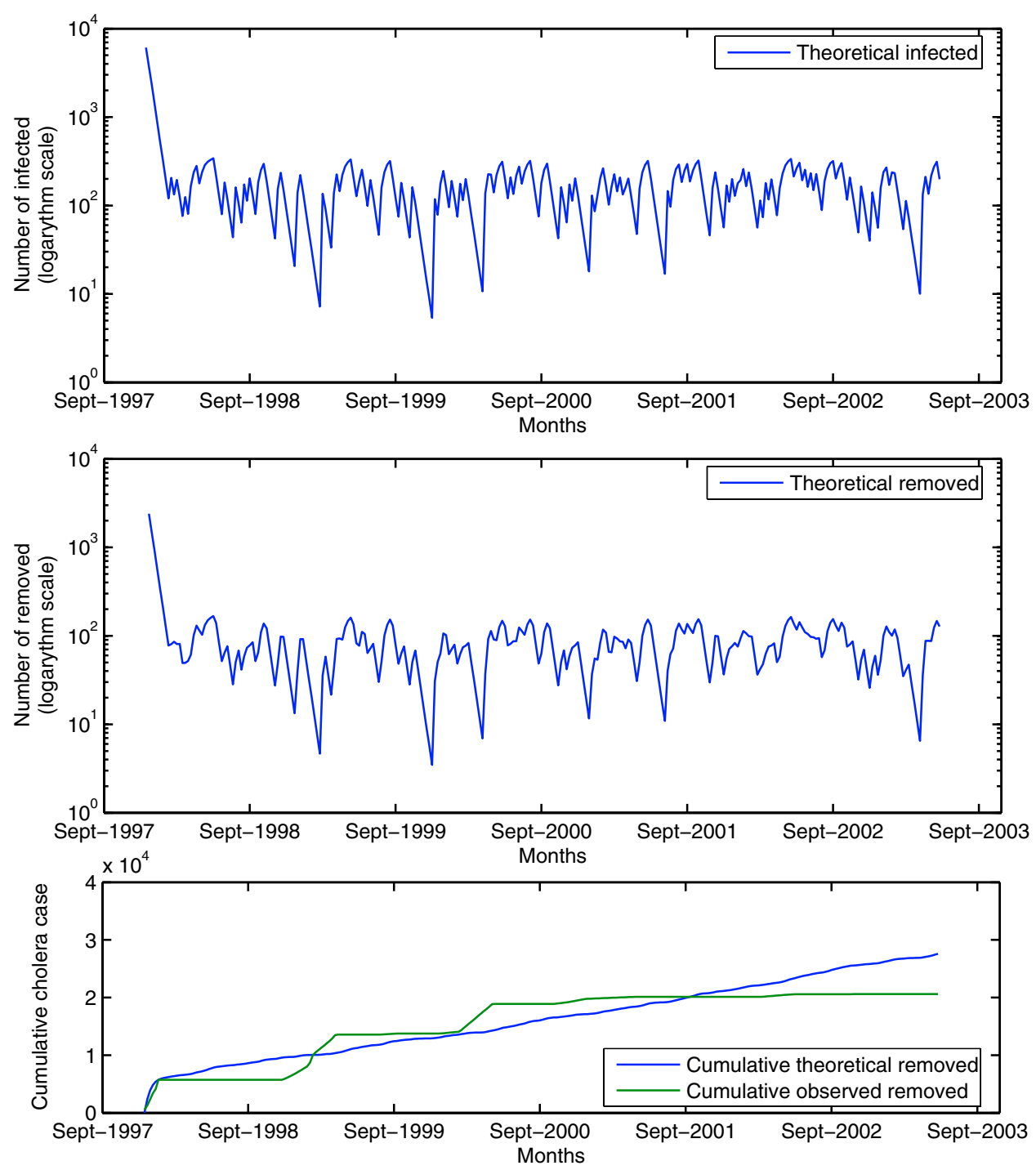

FiguRE 7. Time evolution of three variables of the SIDR model for Somalia, Theoretical Removed, Theoretical Infected, and both Cumulative Theoretical and Observed Removed. 


\section{Discussion and Conclusion}

$V$. cholerae is an environmentally-persistent aquatic microorganism, and several reports have shown that some free living organisms like plants or crustaceans may play the role of environmental reservoirs for this human pathogen $[22,30]$. We need to combine a variety of approaches to tackle the disease in both epidemic and endemic contexts, monitoring the aquatic environment by remote sensing to inform the sanitary policy of one potential risk. In this context, remote sensing and mathematical models can have several functions. They may be phenomenological and descriptive in trying to predict the immediate future [1]. The model we propose and explore here is the first which tries to fit derived chlorophyll concentration and cholera observed data. We started to account for the data collected on the disease using the standard epidemiological model, the Susceptible-Infected-Removed-Death (SIDR) epidemic model. Our model is at the crossroad between two points of view, that of the localists and that of the contagionists, because we assume that a susceptible can be infected by contact either with phytoplankton or with an infected person. Merrell et al. [32] have recently uncovered heightened pathogen infectivity following passage of the pathogen in the human host, which would reinforce the transmission feedback from infected to susceptible individuals. Indeed a high level of chlorophyll a (which is a direct measurement of a bloom and an indirect measurement of bacteria density in marine ecosystem) initiates a epidemic and is relieved by intra-population transmission. The other originality of our model is that we consider temporary immunity initiated by infection; this leads us to introduce a class of recovered. The results show a good correspondence between the observed cholera cases and the output of our models for the two East African countries studied. However, the synchrony between observed and simulated epidemics was not observed and more has to be done to better describe the initiation of a given epidemics.

These preliminary results incite us to propose evolution of this first model:

- Elaborating a discrete time model, with months as time unit (recall that epidemiological data are recorded more or less monthly). Taking stochasticity into account in the dynamics is rather straightforward in discrete time models. This allows to let aside mathematical technicalities of continuous time modelling which are not central.

- A threshold relationship for the impact of chlorophyll a concentration. If the chlorophyll a concentration is lower than a threshold $J_{t}$ (a new parameter to be estimated), the probability of catching cholera by contact with the phytoplankton is null; otherwise, the probability is a function of $C_{t}$.

- Model with asymptomatics: above only 33\% of infected show the symptoms and thus can die because of cholera. Indeed, the other fraction of infected individuals do not develop symptoms (asymptomatics), but they could play a role in the spread of the disease: first, they constitute a human reservoir of bacteria and can infect susceptibles, and second their offspring are immune.

- Multi-level of immunity age-dependent model: we can distinguish three classes of ages: less than 2 years old, between 2 and 18 years old and more than 18 years old. Individuals less than 2 years old are the more resistant face to cholera (immunity from the mother); individuals more than 18 years old are a little less resistant; and the class of individuals between 2 and 18 years old is the least resistance class.

- Time-dependent rates: one can imagine that contact rates (i.e. the parameters $\beta$ and $\gamma$ ) decrease quickly after the start of an epidemic, due to the sensitization of the population by the authorities.

- Modelling different stochastic components, at the epidemiological level (the epidemiological processes) and at the observational level (the data acquisition process). Together with the natural monthly time unit, this is another argument in favor of developing a discrete time model.

In the long term, we wish to construct a new model, based on the same hypothesis than the one presented here, in discrete time and incorporating new phenomena. This new model would include the sea-surface temperature (SST) and precipitation as two predictive parameters. The interest is that we have at disposal longer time series for both precipitation and SST which are more reliable (although these data are also obtained by remote sensing). The goal is to get a dynamics involving both chlorophyll a concentration, SST and precipitation to produce a predictive model of cholera cases based on environmental parameters. 


\section{REFERENCES}

[1] R.M. Anderson and R.M. May. Infectious diseases in humans: dynamics and control. Oxford University Press, Oxford, 1991.

[2] M.L. Bennish. Cholera: Pathophysiology, clinical features, and treatment. In I.K. Wachsmuth, P.A. Blake, and O. Olsvik, editors, V. cholerae and cholera: molecular to global perspectives, pages 229-255. American Society for Microbiology, Washington DC., 1994.

[3] P.A. Blake. Endemic cholera in Australia and the United States. In I.K. Wachsmuth, P.A. Blake, and O. Olsvik, editors, V. cholerae and cholera: molecular to global perspectives, pages 309-319. American Society for Microbiology, Washington DC., 1994.

[4] M. Bradley, R. Shakespeare, A. Ruwende, M.E.J. Woolhouse, E. Mason, and A. Munatsi. Epidemiological features of epidemic cholera (El Tor) in Zimbabwe. Trans. R. Soc. Trop. Med. Hyg., 90: 378-382, 1996.

[5] V. Capasso and S.L. Paveri-Fontana. A mathematical model for the 1973 cholera epidemic in the European Mediterranean region. Rev. Epidém. et Santé Pub., 27: 121-132, 1979.

[6] R.A. Cash, S.I. Music, J.P. Libonati, M.J. Snyder, R.P. Wenzel, and R.B. Hornick. Response of man to infection with Vibrio cholerae. I. Clinical, serologic, and bacteriologic responses to a know inoculum. J. Infect. Dis., 129: 45-52, 1974.

[7] D.A. Chiavelli, J.W. Marsh, and R.K. Taylor. The manose-sensitive hemagglutinin of $V$. cholerae promotes adherence to zooplankton. Appl. Environ. Microbiol., 67: 3220-3225, 2001.

[8] J.D. Clemens, F. van Loon, D.A. Sack, M.R. Rao, F. Ahmed, J. Chakraborty, B.A. Kay, M.R. Kahn, M. Yunus, J.R. Harris, A.-M. Svennerholm, , and J. Holmgren. Biotype as determinant of naturalimmunising effect of cholera. Lancet, 337: 883-884, 1991.

[9] C.T. Codeço. Endemic and epidemic cholera: the role of the aquatic reservoir. BMC Infect. Dis., 1(1), 2001.

[10] R.R. Colwell. Global climate and infectious disease: the cholera paradigm. Science, 274(5295): 2025-2031, 1996.

[11] R.R. Colwell and A. Huq. Environmental reservoir of V. cholerae. Ann. N.Y. Acad. Sci., 740: 44-54, 1994.

[12] R.R. Colwell, A. Huq, B. Lobitz, L. Beck and B. Wood. Remote Sensing of Cholera Outbreaks. CHAART project at http://geo.arc.nasa.gov/sge/health/projects/cholera/cholera.html, 2000.

[13] R.R. Colwell, J.B. Kaper, and S.W. Joseph. V. cholerae, V. Parahaemolyticus and other vibrios: occurence and distribution in Chesapeake Bay. Sciences, 198: 394-396, 1977.

[14] R.R. Colwell and W.B. Spira. The ecology of V. cholerae. In D. Barua and W.B. Greenough, editors, Cholera, number III, pages 107-127. Plenum Medical Book Co., New-York, 1992.

[15] S.M. Faruque, Asadulghani, M.N. Saha, A.R. Alim, M.J. Albert, K.M. Islam and J.J. Mekalanos. Analysis of clinical and environmental strains of nontoxigenic Vibrio cholerae for susceptibility to CTXF: Molecular basis for origination of new strains with epidemic potential. Infect. Immin., 66: 5819-5825, 1998.

[16] E.J. Gangarosa and W.H. Moshley. Epidemiology and surveillance of cholera. In D. Barua and W. Burrows, editors, Cholera, pages 381-403. W. B. Saunders Co, Philadelphia, 1974.

[17] R.I. Glass, S. Becker, M.I. Huq, B.J. Stoll, M.U. Kahn, M.H. Merson, J.B. Lee, and R.E. Black. Endemic cholera in rural Bengladesh, 1966-1980. Am. J. Epidemiol., 116(6): 959-970, 1982.

[18] H.W. Hethcote. The mathematics of infectious diseases. SIAM Rev., 42(4): 599-653, 2000. (electronic).

[19] A. Huq. The role of planktonic copepods in the survival and multiplication of $\mathrm{V}$. cholerae in the environment. $\mathrm{PhD}$ thesis, University of Maryland, College Park, 1984.

[20] A. Huq and R.R. Colwell. Vibrios in the marine and estuarine environment tracking of Vibrio cholerae. J. Ecosyst. Health, 2: 198-214, 1996.

[21] A. Huq, E.B. Small, P.A. West, M.I. Huq, R. Rahman and R.R. Colwell. Ecological relationships between Vibrio cholerae and planktonic crustacean copepods. Appl. Environ. Microbiol., 45: 275-283, 1983.

[22] S.M. Islam, B.S. Drasar, and D.J. Bradley. Long term persistence of toxygenic $V$. cholerae O1 in the musilaginous sheath of a blue-green alga anabaena variabilis. J. Trop. Med. Hyg., 93: 133-139, 1990.

[23] S.M. Islam, B.S. Drasar, and D.J. Bradley. Attachment of toxigenic Vibrio cholerae O1 to various freshwater plants and survival with a filamentous green alga, Rhizoclonium fontanum. J. Trop. Med. Hyg., 92: 396-401, 1989.

[24] S.M. Islam, B.S. Drasar, and D.J. Bradley. Survival of toxigenic Vibrio cholerae O1 with a commun duckweed, Lemna minor, in artificial aquatic ecosystems. Trans. Roy. Soc. Trop. Med., 84: 422-424, 1990.

[25] J.B. Kaper, J.G. Morris JR, and M.M. Levine. Cholera. Clin. Microbiol. Rev., pages 48-86, Jan. 1995.

[26] T. Kiorboe and T.J. Neilson. Copepods. Limnol. Oceanog., 39: 493-507, 1994.

[27] M.M. Levine, R.E. Black, M.L. Clements, L. Cisneros, D.R. Nalin, and C.R. Young. Duration onf infection-derived immunity to cholera. J. Infect. Dis., 143: 818-820, 1981.

[28] M.M. Levine, R.E. Black, M.L. Clements, D.R. Nalin, L.Cisneros, and R.A. Finkelstein. Volunteer studies in development of vaccines against cholera and enterotoxigenic Escherichia Coli: a review. In T. Holme, J. Holmgren, M.H. Merson, and R. Mollby, editors, Acute enteric infections in children. New prospects for treatment and prevention, pages 443-459. Elsevier/NorthHolland Biomedical Press, Amsterdam, 1981. 
[29] M.M. Levine, D.R. Nalin, J.P. Craig, D. Hoover, E.J. Bergquist, D. Waterman, H.P. Holley, R.B. Hornick, N.P. Pierce, and J.P. Libonati. Immunity of cholera in man: relative role of antibacterial versus antitoxic immunity. Trans. R. Soc. Trop. Med. Hyg., 73: 3-9, 1979.

[30] E.K. Lipp, A. Huq, and R.R. Colwell. Effects of global climate on infectious disease: the cholera model. Clin. Microbiol. Rev., 15(4): $757-770,2002$

[31] B. Lobitz, L. Beck, A. Huq, B. Wood, G. Fuchs, A.S.G. Faruque, and R.R. Colwell. Climate and infectious disease: use of remote sensing for detection of vibrio cholerae by indirect measurement. Proc. Natl. Amer. Soc., 97(4): 1438-1443, 2000.

[32] D.S. Merell, S.M. Butler, F. Qadri, N.A. Dolganov, A. Alam, M.B. Cohen, S.B. Calderwood, G.K. Schoolnik, and A. Camilli. Host-induced epidemic spread of the cholera bacterium. Nature, 417: 642-645, 2002.

[33] M. Morillon, J.J. De Pina, J.A. Husser, J.M. Baundet, E. Bertherat, and G. Martet. Djibouti, histoire de deux épidémies de choléra : 1993-1994. Bull. Soc. Path. Ex., 91: 407-411, 1998.

[34] W.H. Mosley. The role of immunity in cholera. A review of epidemiological and serological studies. Tex. Rep. Biol. Med., 27: 227-244, 1969.

[35] W.H. Mosley, W.M. McComack, and A. Ahmed. Report of the 1966-67 cholera field trial in rural east pakistan. 2. result of the serological surveys in the study population-the relationship of case rate to antibody titre ans an estimate of the inapparent infection rate with Vibrio cholerae. Bull. W.H.O., 40: 187-197, 1969.

[36] J.D. Murray. Mathematical biology: 1. An introduction. Springer-Verlag, New-York, 2002.

[37] T. W. Ng, G. Turinici, and A. Danchin. A double epidemic model for the SARS propagation. BMC Infect. Dis., 3(19), 2003.

[38] C. Torrence and G.P. Compo A Practical Guide to Wavelet Analysis. Bull. Amer. Meteor. Soc., 79(1): 61-78, 1998.

[39] J.E. O'Reilly, S. Maritorena, B.G. Mitchell, D.A. Siegel, K.L. Carder, S.A. Graver, M. Kahru, and C. McClain. J. Geophys. Res, 103(C11): 24937-24954, 1998.

[40] M. Pascual, M.J. Bouma, and A.P. Dobson. Cholera and climate: revisiting the quantitative evidence. Microbes Infect., 4: $237-245,2002$.

[41] M. Pascual, X. Rodó, S.E. Ellner, R. Colwell and M.J. Bouma. Cholera dynamics and El Niño-Southern Oscillation. Science, 289: 1766-1769, 2000.

[42] R. Pollitzer. Cholera. World Health Organization, Geneva, 1959.

[43] E. Pourabbas, A.d'Onofrio, and M. Rafanelli. A method to estimate the incidence of communicable diseases under seasonal fluctuations with application to cholera. Appl. Math. Comput., 118(2-3): 161-174, 2001.

[44] W.H. Press and B.P. Flannery and S.A. Teukolsky and W.T. Vetterling. Numerical Recipes in C: The Art of Scientific Computing. Cambridge University Press, Cambridge, 2002.

[45] D.B. Roszak and R.R. Colwell. Survival strategies of bacteria in the natural environment. Microbiol. Rev., 51: 365-379, 1987.

[46] C. Seas, J. Miranda, A.I. Gil, R. Leon-Barua, J. Patz, A. Huq, R.R. Colwell and R.B. Sack. New insights on the emergence of cholera in Latin America during 1991: The Peruvian experience. Am. J. Trop. Med. Hyg., 62: 513-517, 2000.

[47] P. Shears. Cholera. An. Trop. Med. Parasitol., 88(2): 109-122, 1994.

[48] B.N. Shukla, D.V. Singh and S.C. Sanyal. Attachment of non-culturable toxigenic Vibrio cholerae O1, and non-O1, and Aeromonas spp. to the aquatic arthropod Gerris spinolae and plants in the River Ganga, Varanasi. FEMS Immunol. Med. Microbiol., 12: 113-120, 1995.

[49] E.C. Speelmon and W. Checkley ans R.H. Gilman and J. Patz and M. Calderon and S. Manga. Cholera incidence and El Niño-related higher ambient temperature. Journal of the American Medical Association, 283: 3072-3074, 2000.

[50] W.M. Spira, A. Huq, Q.S. Ahmed and Y.A. Saeed. Uptake of Vibrio cholerae biotype El Tor from contaminated water by water hyacynth (Eichhornia ceassipes). Appl. Environ. Microbiol., 44: 1047-1058, 1981.

[51] R.V. Tauxe, E.D. Mintz, and R.E. Quick. Epidemic cholera in the new world: translating field epidemiology into new prevention strategies. Emerg. Infect. Dis., 1(4): 141-146, 1995.

[52] H.R. Thieme. Mathematics in population biology. Princeton Series in Theoretical and Computational Biology. Princeton University Press, Princeton, 2003.

[53] S.J. Utsalo, F.O. Eko, F. Umoh, and A.A. Asindi. Faecal excretion of $V$. cholerae during convalescence of cholera patients in Calabar, Nigeria. European Journal of Epidemiology, 15: 379-381, 1999. 